\title{
Development and Validation of Preschool Teachers' Caring Behaviour Questionnaire and Its Internal Mechanism with Work Performance
}

\author{
Juan Han ${ }^{*}$, Xiaolan Luo², Haohan Luo ${ }^{3}$ \\ ${ }^{1}$ School of Education Science, Shanxi Normal University, Linfen, China \\ ${ }^{2}$ Department of Education, Xinzhou Normal University, Xinzhou, China \\ ${ }^{3}$ Fujiayan Primary and Secondary Schools, Yichang, China \\ Email: hjuaner1205@163.com
}

How to cite this paper: Han, J., Luo, X. L., \& Luo, H. H. (2021). Development and Validation of Preschool Teachers' Caring Behaviour Questionnaire and Its Internal Mechanism with Work Performance. Open Journal of Social Sciences, 9, 484-508. https://doi.org/10.4236/jss.2021.92032

Received: January 25, 2021

Accepted: February 23, 2021

Published: February 26, 2021

Copyright $\odot 2021$ by author(s) and Scientific Research Publishing Inc. This work is licensed under the Creative Commons Attribution International License (CC BY 4.0).

http://creativecommons.org/licenses/by/4.0/

\begin{abstract}
Purpose: Firstly, the Caring Behaviour Questionnaire for Preschool Teachers was developed to facilitate formal assessment of preschool teachers' caring quality. Caring behavior, as an important performance of preschool teachers' caring quality, can reflect the real state of preschool teachers' caring. The research on the structure and present situation of preschool teachers' caring behavior is not only the exploration of caring theory, but also conducive to the professional development of preschool teachers. Here we report the development and initial validation. Secondly, the relationship model of the four variables of preschool teachers' caring behavior, competence, occupational happiness and job performance is established to explore the internal mechanism of the effect of preschool teachers' caring behavior on job performance. Methods: Firstly, the initial item pool was developed based on a theoretical framework, empirical literature, existing scales and expert review. The Caring Behavior Questionnaire for Preschool Teachers (CBQPT) was developed from the thematic analysis of open questionnaire surveys with preschool teachers. The questionnaire was conveniently distributed to 80 front-line preschool teachers from 8 kindergartens in Xinzhou city. Exploratory factor analysis was utilized to explore domains in the questionnaire. Construct and convergent validity data, internal consistency and composite reliability of the domains were analyzed. Demographic data and preschool teachers' characteristics were collected. Secondly, participants were 500 Chinese preschool teachers who reported measures of the current situation of kindergarten teachers' caring behaviors, self-assessment questionnaire for teachers' competence, work performance and occupational happiness. Structural equation modeling and
\end{abstract}


bootstrap mediation tests were used. Results: Firstly, four-hundred and fifty-four preschool teachers completed the questionnaire of preschool teachers' caring behavior. The final questionnaire of preschool teachers' caring behavior has 19 items under five internally-consistent and reliable domains: understanding and support, class management, communication, respect and trust, reflection and promotion. The full scale demonstrated good internal consistency $(\propto=0.94)$, composite reliability of the domains, acceptable convergent, divergent validity, good construct and convergent validity. The internal consistency coefficient of the questionnaire was 0.940 , class management 0.741 , understanding and support 0.855 , communication 0.820 , respect and trust 0.825 , reflection and promotion 0.814 respectively. The reliability and validity of the questionnaire meet the requirements of measurement. This questionnaire was used to measure 484 kindergarten teachers. Secondly, the results showed that teachers' caring behavior significantly positively predicted work performance in preschool teachers. Competence and occupational happiness were found to play a mediating role between teachers' caring behavior and work performance in preschool teachers. Conclusions: Firstly, initial evaluation shows the CBQPT has good validity and reliability and is a promising tool for the measure of current situation of preschool teachers' caring behavior towards children. The results showed that the overall caring behavior level of kindergarten teachers was high, and the average score from the highest to the lowest was understanding and support, respect and trust, class management, reflection and promotion, communication. In educational background, there is no significant difference in preschool teachers' caring behavior. There are significant differences in preschool teachers' caring behavior in teaching age, marital status, school location and school nature. Preschool teachers' caring behavior in public schools is significantly higher than that in private schools. Married preschool teachers' caring behavior is significantly higher than unmarried preschool teachers' caring behavior. Urban preschool teachers' caring behavior is significantly higher than rural preschool teachers' caring behavior. Public schools' caring behavior is significantly higher than private kindergarten teachers' caring behavior. Secondly, the study expands the understanding of the mechanisms underlying the effect of teachers' caring on work performance by the mediating roles of competence and occupational happiness, and its findings are novel and insightful, both theoretically and practically. This study not only clarifies that preschool teachers' caring behavior positively predicts work performance but also supports the roles of their competence and occupational happiness as mediators in this relationship.

\section{Keywords}

Preschool Teachers, Caring Behavior, Questionnaire Development, Competence, Occupational Happiness, Work Performance

\section{Introduction}

Since the 1980s, teachers' professional development has gradually become a 
widespread concern of researchers. As for the definition of teacher professional development, there are great differences among researchers, but most of them believe that the ultimate goal of teacher professional development is to improve students' learning achievement by improving teachers' performance (Ke \& Cui, 2013). It is found that the research on "teacher performance" is related to both poor and good performance of teachers (Lei, 2015), in the current prevalence of positive psychology, especially emphasis on teachers' positive behavior.

In his report to the 19th National Congress of the Communist Party of China (CPC), General Secretary Xi Jinping put forward seven requirements for people's livelihood that must achieve "new progress". This shows that early childhood education has been formally proposed as an important livelihood issue of high concern to the Party and the country. It is of great significance for the country, society and the people to have children. Preschool education is not only an important issue affecting the future of the country, but also a key link of the country's future competition strategy. It is also a valuable asset to build the future of the country. At the same time, it is related to people's satisfaction with preschool education and their vital interests. However, in recent years, "kindergarten incidents" have become common occurrences in China, frequently appearing in newspapers and even making headlines on the Internet, which has exposed many problems in China's early childhood education. The Ministry of Education is striving to make new progress in the field of "raising children" and has adopted five measures, one of which is to strengthen the construction of teachers' morality and style. At the same time, teacher's love, as the soul of teacher's morality, must be the most important part of teacher morality construction. Considering the age characteristics of children, is a lack of self-protection awareness and ability of the group, preschool teachers must be full of love, can pay care for children. In the 1990s, The American scholar Nell Noddings proposed that the primary job of schools was to care for students (Bloom \& Noddings, 1996). He pointed out that caring must be accomplished through specific caring acts ( $\mathrm{Wu}, 2012)$. From the practice of the "Caring Teacher and Child Training Program" in the University of South Carolina, it can be seen that caring is an essential and important quality for preschool teachers (Freeman, Swick, \& Brown, 1999; Kaiser \& Rice, 1974). Therefore, the caring behavior of preschool teachers begins to receive much attention.

Preschool teachers' caring behavior should consider how to care for children rationally and scientifically, which requires preschool teachers to keep learning. Therefore, the clear and standard of caring behavior for preschool teachers is an important link to promote the construction of teacher ethics, enhance the professional development of preschool teachers, and reduce the bad behavior of preschool teachers. It is found in the literature search that at present, educational ethics researchers at home and abroad mainly focus on theoretical research on the construction of preschool teachers' caring behavior, and empirical research is rarely involved. Therefore, under the current situation of the current lack of 
preschool teachers' caring behavior, urgently need a kind of effective tools and instruments to measure the caring behavior of preschool teachers, explore the measure of preschool teachers' caring behavior and dimensions, let preschool teachers' caring behaviors, care methodology will, in order to promote preschool teachers behavior standards, promote the development of the professional level. For this purpose, a new instrument has to be developed and examined.

This study focused on the correlation among teachers' caring behavior, competence, occupational happiness and work performance and tested whether competence and occupational happiness mediate between teachers' caring behavior and work performance. Participants were 500 Chinese preschool teachers who reported measures of the current situation of kindergarten teachers' caring behaviors, self-assessment questionnaire for teachers' competence, work performance and occupational happiness .Structural equation modeling and bootstrap mediation tests were used. The results showed that teachers' caring behavior significantly positively predicted work performance in preschool teachers. Competence and occupational happiness were found to play a mediating role between teachers' caring behavior and work performance in preschool teachers.

\section{Research Design}

\subsection{Scale Development: Studies 1 and 2}

\subsubsection{Study 1: Item Generation}

Firstly, an open questionnaire survey was conducted to understand the caring behavior of 80 preschool teachers from 8 kindergartens in Xinzhou city. It mainly includes the way kindergarten teachers care for children, and the influence of kindergarten teachers' caring behavior on the relationship between teachers and children. In addition to basic information such as gender, class, position, subject taught, and kindergarten, the questionnaire mainly includes specific questions such as "How is your relationship with children? Can you give some examples?" What are your approaches to children's understanding and what are the contents?" "In what ways do you think a child's growth needs are being met and how do you meet those needs?" "How do you manage the kids in your class?" "What do you do when a child is in trouble? For example, in life, in study, in communication with peers, and so on, please give detailed examples." "How do you care about children in your communication with them? Please describe it in terms of words, feelings, thoughts, actions and results." "How do you deal with children's bad behavior, such as your attitude, how do you deal with it? Please describe it in detail." "What do you think a caring preschool teacher is? Please talk." Eight questions.

Then, analyze the collected through open questionnaire problem sorting and analysis, divided into different aspects of preschool teachers' caring behavior, then invite four psychology of professional teachers, three preschool education teachers review project topic and appraise to the accuracy of the item to express, and invited 10 first-line teachers read ask volume, points out that the signific- 
ance of the topic and modify. On this basis, the initial questionnaire of preschool teachers' caring behavior was constructed.

\subsubsection{Study 2: Item Reduction and Scale Construction}

In study 2, participants completed the full 36 item CBQPT as described below. The suitability or reliability of individual items in the self-made questionnaire was tested through item analysis. The item analysis of the kindergarten teachers' caring behavior questionnaire mainly conducted data tests such as extreme group comparison, correlation between questions and total scores, homogeneity test (a value after questions were deleted, commonality, factor load) and so on. In this Under the standard, questions 4, 6 and 20 in the initial questionnaire do not meet the standard, while other items do. Therefore, questions 4, 6 and 20 are deleted, leaving 33 questions.

Exploratory factor analysis was carried out for the remaining 33 questions, and the KMO value (Kaiser-Meyer-Olkin) and the chi-squared value of Bartlett's spherical test were used to test whether the variables represented by the data were correlated with each other. After analysis, it was found that the KMO value was 0.903 and the KMO value was greater than 0.60 (Kaiser \& Rice, 1974), the chi-square value of Bartlett's spherical test was 2681.681, and the degree of freedom was 528 , reaching a significant level of 0.05 , indicating that the data was suitable for factor analysis (Wu, 2010). Principal component analysis (PCA) was used to extract the factors, and the maximum variation method was used to analyze the axis of rotation, and the factor with the characteristic value greater than 1 was extracted. According to the principle of item deletion, items 5, 7, 8, $10,12,14,15,19,23,27,29,33,34$ and 36 were deleted. Finally, 19 items were obtained, including five factors, and the variation of interpretation was $57.717 \%$.

\subsection{Studies 3: Evaluation and Validation}

Participants in study 3 completed the reduced 19 item CBQPT as described below. Confirmatory factor analysis and Cronbach's alpha coefficients were used to examine the reliability and construct validity of the scale. The date of study 3 were then analysed using Confirmatory factor analysis, internal consistency (Cronbach's alpha); the composition reliability of each dimension and convergent validity (correlation).

\subsection{Status Analysis for Preschool Teachers and Its Relations to Competence, Occupational Happiness and Work Performance: Studies 4 and 5}

Studies 4 and 5 were conducted consecutively. In study 4 and 5, participants completed the full 19 item kindergarten teachers' caring behaviors, self-assessment questionnaire for preschool teachers' competence, work performance questionnaire for preschool teachers and occupational well-being questionnaire for preschool Teachers.

The present study, using a structural equation modeling approach, attempts to 
address this gap by exploring teachers' caring behaviour and its relations to competence, occupational happiness and work performance in China.

\section{Methods}

\section{Procedures and Participants}

Study 1 participants were 80 front-line preschool teachers from 8 kindergartens in Xinzhou city for the preparation of the questionnaire, including 1 municipal kindergarten, 3 district-level kindergartens and 4 ordinary kindergartens. 80 questionnaires were issued, 78 were recovered and 74 were valid. The recovery rate and effective rate were $97.5 \%$ and $92.5 \%$ respectively.

Study 2 participants were 245 front-line preschool teachers from Xinzhou and Luliang in Shanxi Province for the structural analysis of the initial questionnaire. After eliminating invalid questionnaires, 212 valid questionnaires were recovered, with a recovery rate of $86.531 \%$. Among them, there are 12 male preschool teachers, 200 female preschool teachers, 153 public preschool teachers and 59 private preschool teachers.

Study 3 participants were 260 preschool teachers from Changzhi city, Taiyuan City and Datong City of Shanxi Province for confirmative factor analysis of the initial questionnaire. Invalid questionnaires were eliminated, and 242 valid questionnaires were recovered, with a recovery rate of $93.077 \%$.

Study 4 and 5 participants were 500 preschool teachers from Xinzhou, Taiyuan, Luliang and Changzhi in Shanxi Province for the formal measurement of the current situation of kindergarten teachers' caring behaviors, self-assessment questionnaire for preschool teachers' competence, work performance questionnaire for preschool teachers and occupational well-being questionnaire for preschool Teachers.

The invalid questionnaires were eliminated, and 484 valid questionnaires were recovered, with a recovery rate of $96.8 \%$. The average age of teachers was 28.570 \pm 7.379 .

Analyses were conducted using the Statistical Package for Social Sciences (IBM SPSS; version24). Questionnaires were distributed through the network questionnaire star, SPSS24.0 was used for data input and analysis, and Amos24.0 was used for statistical analysis of structural equation model, including descriptive statistical difference test, variance analysis, Pearson correlation analysis and partial correlation.

\section{Instruments}

In the study 1 , through consulting literature materials, an open questionnaire was prepared. A questionnaire survey was conducted among 80 front-line preschool teachers, and 56 items reflecting the caring behavior of kindergarten teachers were obtained, and 49 items were obtained after preliminary screening. After four psychology professional teachers, three preschool education examination project title and the expression of item after verification, the accuracy of the 
invited 10 first-line teachers read the questionnaire and points out that the significance of the topic and modify, preliminary construction of preschool teachers' caring behavior of the initial questionnaire is made up of 36 projects, using the five point likert scale score, "1" represents very does not conform to, "2" is not conform to, " 3 " on behalf of the general accord with, "4" on behalf of the match, " 5 " is very accord with.

In the study 4 and 5, a questionnaire with four scales was employed in the present study. All items in the questionnaire were scored on a 5-point Likert scale from 1 (strongly disagree) to 5 (strongly agree). Participants completed the questionnaire and they provided basic demographic information such as marital status, level of education, education years, school location, school nature. The four scales were:

\subsection{Questionnaire on Kindergarten Teachers' Caring Behavior}

The questionnaire of preschool teachers care behavior, a total of 19 questions, including the five dimensions, and dimension of classroom management includes three topics including six questions, understanding and support dimension communication dimensions including four questions, respect and trust dimension includes three questions, reflection and ascend dimensions including three questions questionnaire using 5 points, one representative is not conform to the 2 representative don't comply with the three representative general 4 representative compared with five representative very much in the questionnaire all dimensions and total score of Cronbach alpha coefficient is $0.741,0.855,0.820$, $0.825,0.814,0.940$.

\subsection{Self-Assessment Questionnaire for Preschool Teachers' Competence}

Zhu Xiaoying establishment of preschool teachers' competence self assessment questionnaire includes four dimensions, respectively is the education ability (children's concept of teaching skills, teaching strategy knowledge class management ability) attitude, self-efficacy occupation moral self-reflection) psychological characteristics (role monitoring ability interpersonal responsibility and motivation, achievement motivation vocational satisfaction), a total of 38 project (Zhu, 2007) the questionnaire adopts Likert 5 point scoring method, one representative is not conform to the two representative don't conform to the three representative general four representative compared with 5 representative very accord with the larger the number is, the more consistent the behavior is with the kindergarten teacher's own daily behavior or concept score; the higher the score is, the higher the kindergarten teacher's competence level is; the higher the Cronbachs coefficient of each dimension and total score of the questionnaire is $0.895,0.934,0.848,0.881,0.965$.

\subsection{Work Performance Questionnaire for Preschool Teachers}

Xiao (2012) of the revision of the teachers' job performance scale contains three 
dimensions, respectively is 18 project work dedication interpersonal and task performance questionnaire adopts Likert5 point scoring method, one representative is not conform to the two representative don't conform to the three representative general four representative compared with 5 representative said very accord with the higher score the preschool teachers' job performance, the higher the questionnaire of each dimension and total score of Cronbach alpha coefficient is $0.906,0.874,0.867,0.955$.

\subsection{Occupational Well-Being Questionnaire for Preschool Teachers}

Regulates revision of preschool teachers' professional happiness scale includes four dimensions, well-being and psychological well-being emotional well-being society cognitive well-being, a total of 15 projects (Wang, 2013), the questionnaire adopts Likert5 point scoring method, one representative is not conform to the 2 representative is not in line with the three representative general 4 representative compared with five representative very much in the greater the number indicates that the questionnaire of preschool teachers' professional happiness level of each dimension and the total score of Cronbach alpha coefficient is $0.821,0.835,0.812,0.810,0.940$.

\section{Data Analysis}

\subsection{Results Study 2}

\subsubsection{Exploratory Factor Analysis}

Thirty-three items were entered into the EFA. Following listwise deletion based on all variables, $\mathrm{N}=212$ (COSMIN guidelines consider an item to participant ratio of 1:5 to be "good"; this ratio is 1:11 (Mokkink et al., 2010). The KMO value (Kaiser-Meyer-Olkin) and the chi-squared value of Bartlett's spherical test were used to test whether the variables represented by the data were correlated with each other. Bartlett's test of sphericity was significant at $<0.05$ and the Kaiser-Meyer-Olkin (KMO) value was 0.903 and the KMO value was greater than 0.60 (Kaiser \& Rice, 1974), the chi-square value of Bartlett's spherical test was 2681.681 , and the degree of freedom was 528 , reaching a significant level of 0.05 , confirming that the data was suitable for factor analysis (Wu, 2010). All items had above threshold $(>0.7)$ MSA suggesting adequate communality with other variables.As can be seen from the scree plot in Figure 1.

By comparing the results of multiple exploratory factor analysis, it is considered that 5 factors are more suitable to be retained. Principal component analysis (PCA) was used to extract the factors, and the maximum variation method was used to analyze the axis of rotation, and the factor with the characteristic value greater than 1 was extracted. According to the principle of item deletion, items $5,7,8,10,12,14,15,19,23,27,29,33,34$ and 36 were deleted. Consideration of the scree plot suggested that 5 factors might be retained explaining $15.564,11.114,10.703,10.578$ and $9.759 \%$ of variance respectively $(57.717 \%$ total 
variance). The factor load table after rotation is shown in Table 1.

According to the results of exploratory factor analysis, there are five factors in preschool teachers' caring behaviors, which are named as understanding and support, communication, respect and trust, reflection and promotion and class management respectively according to the included projects. Explanation and support mainly describe the attention, encouragement, help and guidance of preschool teachers to children to promote their growth and progress; Communication mainly describes the communication and interaction between preschool teachers and children through language. Respect and trust mainly describe the close interaction between preschool teachers and children as well as tolerance and guidance for children's bad behavior. Reflection and promotion mainly describe the idea and promotion way that preschool teachers should have in order to promote their own caring ability; Class management mainly describes the kindergarten teachers' attitudes and ways to treat children in their activities and learning. The kindergarten teacher's caring behavior is defined as the behavior that the kindergarten teacher, on the basis of understanding, respecting and trusting children, uses appropriate ways to interact with children and implement class management, and can constantly reflect on and improve the ability to care for children.

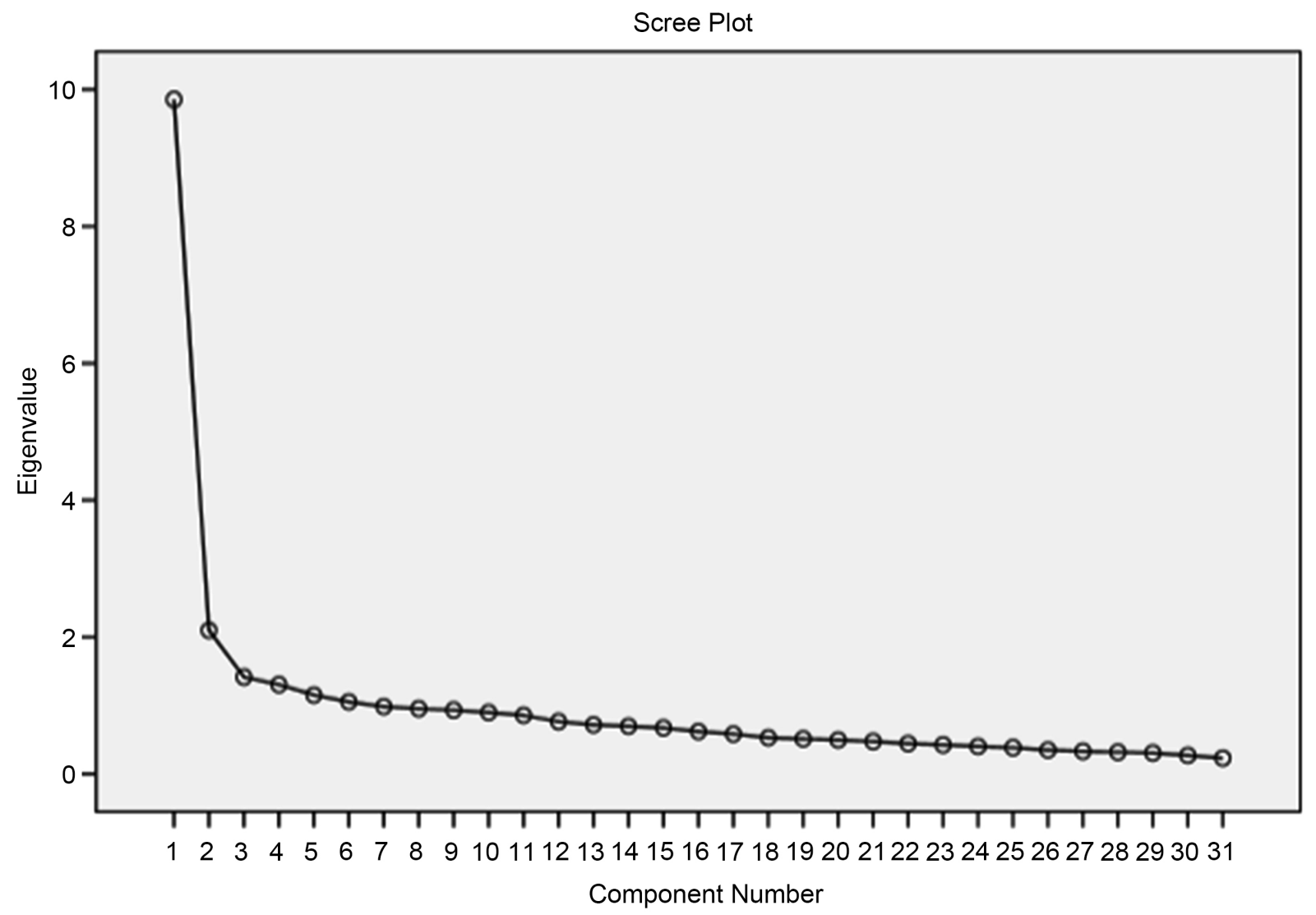

Figure 1. The screen plot for the repeated PCA. A clear demonstration of the elbow of the screen plot. Seven factors emerged with eigenvalue more than 1 . Five factor-solution would be the best factor solution according the screen plot. 
Table 1. Item factor loading.

\begin{tabular}{|c|c|c|c|c|c|c|}
\hline \multirow{2}{*}{ Item } & \multicolumn{6}{|c|}{ Component } \\
\hline & 1 & 2 & 3 & 4 & 5 & Common degrees \\
\hline $\begin{array}{l}\text { E26 Gives positive reinforcement (praise or reward) } \\
\text { to young children for good behavior. }\end{array}$ & 0.718 & & & & & 0.323 \\
\hline $\begin{array}{l}\text { E28 After children do wrong things, they will analyze the } \\
\text { causes together with them and give them correct guidance. }\end{array}$ & 0.651 & & & & & 0.364 \\
\hline E35 Encourage young children with words or actions. & 0.597 & & & & & 0.443 \\
\hline E3 treats each child equally. & 0.594 & & & & & 0.267 \\
\hline $\begin{array}{l}\text { E25 helps young children overcome difficulties and } \\
\text { work hard to complete tasks. }\end{array}$ & 0.562 & & & & & 0.236 \\
\hline $\begin{array}{l}\text { E24 by observing children, reflect on and adjust } \\
\text { their caring behaviors. }\end{array}$ & 0.526 & & & & & 0.270 \\
\hline $\begin{array}{l}\text { E18 has positive emotional communication and } \\
\text { interaction with children. }\end{array}$ & & 0.791 & & & & 0.211 \\
\hline $\begin{array}{l}\text { E21 communicate and communicate with children } \\
\text { on the choice of activity theme. }\end{array}$ & & 0.630 & & & & 0.241 \\
\hline E17 responds patiently to children's questions. & & 0.591 & & & & 0.304 \\
\hline E16 Repeat class rules to young children in a positive tone. & & 0.478 & & & & 0.333 \\
\hline $\begin{array}{l}\text { E31 can feel children's understanding and } \\
\text { recognition of my concern. }\end{array}$ & & & 0.800 & & & 0.235 \\
\hline E30 Hug or show love to your child. & & & 0.637 & & & 0.267 \\
\hline $\begin{array}{l}\text { E32 expresses understanding and tolerance for } \\
\text { children's bad behavior. }\end{array}$ & & & 0.545 & & & 0.447 \\
\hline $\begin{array}{l}\text { E11 improves the ability to care for children by } \\
\text { actively participating in relevant training. }\end{array}$ & & & & 0.796 & & 0.253 \\
\hline $\begin{array}{l}\text { E13 Enrich the way of caring for children by } \\
\text { communicating with other teachers. }\end{array}$ & & & & 0.694 & & 0.280 \\
\hline $\begin{array}{l}\text { E9 pays attention to all aspects of children's development } \\
\text { (physical, psychological, moral conduct, } \\
\text { interests and hobbies, Learning ability, etc. }\end{array}$ & & & & 0.530 & & 0.379 \\
\hline E2 listen to children's problems and troubles. & & & & & 0.851 & 0.271 \\
\hline $\begin{array}{l}\text { E1 can be based on the children's different needs } \\
\text { to adopt the appropriate way of care. }\end{array}$ & & & & & 0.792 & 0.257 \\
\hline E22 Can fairly praise and punish children. & & & & & 0.650 & 0.245 \\
\hline Characteristic Value & 5.780 & 1.605 & 1.243 & 1.220 & 1.118 & \\
\hline Contribution rate & 15.564 & 11.114 & 10.703 & 10.578 & 9.759 & \\
\hline Cumulative contribution rate & 15.564 & 26.677 & 37.380 & 47.958 & 57.717 & \\
\hline
\end{tabular}


Delete the question "focusing on children's development in all aspects (physical, psychological, moral conduct, interests and hobbies, learning ability, etc.)" from the reflection and promotion factors. This question does not conform to the definition of reflection and promotion factors, so it is more appropriate to delete it. Since there are fewer questions in the dimensions of reflection and ascension in the initial questionnaire, a new question is added according to the definition of reflection and ascension, which is entitled "Can feel children's willingness to accept my care". In the end, 19 questions were determined, and the deleted and added questions were evaluated and approved by the psychological experts again, which were considered to conform to the operational definition and the definition of various factors. There are three questions about class management, six questions about understanding and support, four questions about communication, three questions about respect and trust, and three questions about reflection and promotion.

\subsection{Results Study 3}

Study 3 participants were 260 preschool teachers from Changzhi city, Taiyuan City and Datong City of Shanxi Province for confirmative factor analysis of the initial questionnaire (see Figure 2). Invalid questionnaires were eliminated, and 242 valid questionnaires were recovered, with a recovery rate of $93.077 \%$.

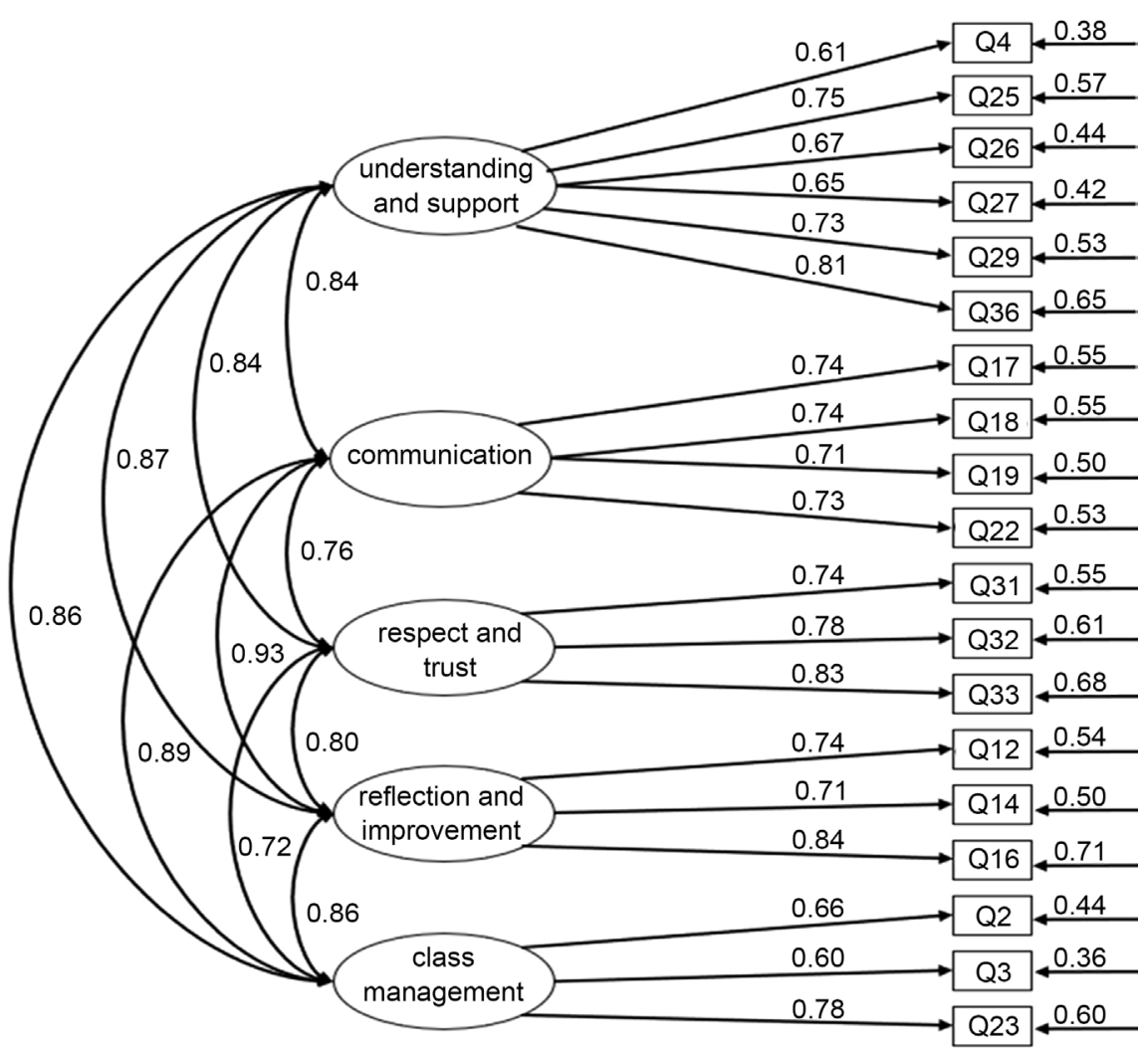

Figure 2. The hierarchical structure of CBQPT. Confirmatory factor analysis with standardized coefficients. Note. Numbers next to the shortcut of the scales correspond to order each items within the scales. 
Study 3 was tested and the questionnaire quality was analyzed. The statistical analysis results showed that the coefficient of Clonbach among the 19 items was 0.940 , class management 0.741 , understanding and support 0.855 , communication 0.820 , respect and trust 0.825 , and reflection and improvement 0.814 , indicating that the questionnaire had a high internal consistency reliability. The correlation between the total score of the questionnaire and various factors reached the significance level of 0.01 (see Table 2). The correlation between the scores of each item and the total score was calculated at the significance level, indicating that the questionnaire had high content validity (see Table 3).

Table 2. Study 3 parameter estimates, 5 factor CFA.

\begin{tabular}{|c|c|c|c|c|c|c|c|c|c|}
\hline \multirow{2}{*}{ Construct } & \multirow{2}{*}{ Item } & \multicolumn{5}{|c|}{ Sig.of estimated parimeter } & \multirow{2}{*}{$\begin{array}{c}\begin{array}{c}\text { Item } \\
\text { reliability }\end{array} \\
\text { SMC }\end{array}$} & \multirow{2}{*}{$\begin{array}{c}\begin{array}{c}\text { Composite } \\
\text { reliability }\end{array} \\
\mathrm{CR}\end{array}$} & \multirow{2}{*}{$\begin{array}{c}\begin{array}{c}\text { Convergence } \\
\text { validity }\end{array} \\
\text { AVE }\end{array}$} \\
\hline & & Unstd & S.E. & z-value & $\mathrm{P}$ & Std & & & \\
\hline \multirow{6}{*}{$\begin{array}{l}\text { understanding } \\
\text { and support }\end{array}$} & e3 & 1.000 & & & & 0.614 & 0.377 & 0.856 & 0.499 \\
\hline & e24 & 1.259 & 0.094 & 13.358 & $* * *$ & 0.753 & 0.567 & & \\
\hline & e25 & 1.131 & 0.093 & 12.209 & $* * *$ & 0.666 & 0.444 & & \\
\hline & e26 & 1.063 & 0.089 & 11.977 & $* * *$ & 0.650 & 0.423 & & \\
\hline & $\mathrm{e} 28$ & 1.177 & 0.090 & 13.061 & $* * *$ & 0.730 & 0.533 & & \\
\hline & e35 & 1.254 & 0.089 & 14.010 & $* * *$ & 0.807 & 0.651 & & \\
\hline \multirow{4}{*}{ communication } & e16 & 1.000 & & & & 0.743 & 0.552 & 0.820 & 0.533 \\
\hline & $\mathrm{e} 17$ & 0.960 & 0.060 & 15.985 & $* * *$ & 0.741 & 0.549 & & \\
\hline & $\mathrm{e} 18$ & 0.965 & 0.064 & 15.164 & $* * *$ & 0.705 & 0.497 & & \\
\hline & $\mathrm{e} 21$ & 1.053 & 0.067 & 15.725 & $* * *$ & 0.730 & 0.533 & & \\
\hline \multirow{3}{*}{ respect and trust } & e30 & 1.000 & & & & 0.739 & 0.546 & 0.825 & 0.612 \\
\hline & e31 & 0.897 & 0.055 & 16.276 & $* * *$ & 0.781 & 0.610 & & \\
\hline & e32 & 0.911 & 0.053 & 17.083 & $* * *$ & 0.825 & 0.681 & & \\
\hline \multirow{3}{*}{$\begin{array}{l}\text { reflection and } \\
\text { Promotion }\end{array}$} & e11 & 1.000 & & & & 0.736 & 0.542 & 0.808 & 0.585 \\
\hline & e13 & 0.848 & 0.056 & 15.184 & $* * *$ & 0.708 & 0.501 & & \\
\hline & e15 & 1.000 & 0.055 & 18.142 & $* * *$ & 0.843 & 0.711 & & \\
\hline \multirow{4}{*}{ class management } & e1 & 1.000 & & & & 0.660 & 0.436 & 0.721 & 0.466 \\
\hline & e2 & 0.818 & 0.072 & 11.429 & $* * *$ & 0.600 & 0.360 & & \\
\hline & $\mathrm{e} 22$ & 1.074 & 0.076 & 14.065 & $* * *$ & 0.776 & 0.602 & & \\
\hline & & & & $\geqq 1.96$ & & $\geqq 0.600$ & $\geqq 0.360$ & $\geqq 0.700$ & $\geqq 0.360$ \\
\hline
\end{tabular}

${ }^{* * *} p<0.001$ level (2-tailed). 
Table 3. Coeffificient of reliability of the factors $(n=500)$.

\begin{tabular}{cc}
\hline Factors & Coeffificient of Reliability (Cronbach's Alpha) \\
\hline Understanding and support & 0.855 \\
Communication & 0.820 \\
Respect and trust & 0.825 \\
Reflection and Promotion & 0.814 \\
Class management & 0.741 \\
CBQPT & 0.940 \\
\hline
\end{tabular}

The purpose of Study 3 is to evaluate the $\mathrm{ft}$ of the five-scale model developed in Study 2 through a confrmatory factor analysis (CFA). A confirmatory factor analysis of the five-factor structure using the lavaan package in $\mathrm{R}$ indicated a reasonable model $\mathrm{ft}(\mathrm{cmin} / \mathrm{df}=2.166, \mathrm{RMSEA}=0.070, \mathrm{CFI}=0.933, \mathrm{SRMR}=$ 0.047).

All parameters loaded significantly on their expected factors $(p<0.01$ in all cases, see Table 2).

Std said standardized factor load, generally above 0.6 is acceptable, SMC said each item reliability, above 0.36 is acceptable, can be found from Table 2 factors in quantity of each item in the formal questionnaire between $0.600-0.843$, the reliability between $0.360-0.711$, shows that the formal questionnaire of each item is of high reliability and explain ability.CR value represents the constituent reliability of all items, and represents the internal consistency of the dimension index, equivalent to Cronbach. The higher CR value represents the higher internal consistency of the dimension, and 0.7 is the acceptable threshold (Fornell, 1981). From Table 2, it can be found that the composition reliability of each dimension in the formal questionnaire is between 0.721 and 0.856 , indicating that each dimension of the formal questionnaire has a good internal consistency reliability and structural validity (Fornell, 1981; Hair et al., 2009).

AVE is the average explanatory ability of calculating latent variables to measured variables, and the higher AVE is, the higher convergence validity of the dimension is. Fornell (1981) suggested that the threshold should be greater than 0.5 , and $0.36-0.50$ were acceptable thresholds. From Table 2, it can be found that the convergence validity of each dimension of the formal questionnaire ranges from 0.466 to 0.612 , indicating that each dimension of the formal questionnaire has a high explanatory ability for the items included (Fornell, 1981). It can be used as a measuring tool for preschool teachers' caring behavior. These results provide strong support for the five-factor model developed in Study 2.

We calculated coefficient of reliability (Table 3 ) based on Cronbach's alpha for each of the five factors, where values above 0.6 indicate acceptable reliability.

Next, we show the results of correlations between each of the five factors with Cronbach's alpha $\geq 0.6$ to one another (to measure discriminant validity), total CBQPT score (to measure convergent validity). The results are shown in Table 4. 
Table 4. Pearson correlation matrix for the scales.

\begin{tabular}{|c|c|c|c|c|c|c|}
\hline Scales & $\begin{array}{c}\text { Total CBQPT } \\
\text { Scores }\end{array}$ & $\begin{array}{l}\text { Understanding } \\
\text { and support }\end{array}$ & Communication & $\begin{array}{l}\text { Respect } \\
\text { and trust }\end{array}$ & $\begin{array}{l}\text { Reflection and } \\
\text { Promotion }\end{array}$ & $\begin{array}{c}\text { Class } \\
\text { management }\end{array}$ \\
\hline Total CBQPT Scores & 1 & & & & & \\
\hline Understanding and support & $0.905^{* *}$ & 1 & & & & \\
\hline communication & $0.879^{* *}$ & $0.706^{* *}$ & 1 & & & \\
\hline Respect and trust & $0.795^{\star *}$ & $0.662^{\star *}$ & $0.615^{\star *}$ & 1 & & \\
\hline Reflection and Promotion & $0.862^{\star *}$ & $0.711^{* *}$ & $0.736^{* *}$ & $0.624^{* *}$ & 1 & \\
\hline Class management & $0.801^{* *}$ & $0.657^{* *}$ & $0.669^{* *}$ & $0.532^{\star *}$ & $0.628^{* *}$ & 1 \\
\hline
\end{tabular}

${ }^{*} p<0.05$ (2-tailed); ${ }^{* *} p<0.01$ (2-tailed); Pearson correlation coeffificients $(\mathrm{n}=500)$.

The correlation between the dimensions of well-structured questionnaires and the total score was between 0.3 and 0.8 , while the correlation between the dimensions was between 0.1 and 0.6 , which was a moderate correlation. Table 4 shows the correlation matrix among various dimensions of the questionnaire on kindergarten teachers' caring behavior. It can be found from the data that the correlation coefficient among various dimensions of the questionnaire is between 0.532 and 0.711 , showing a moderate correlation. The correlation coefficient between each dimension and the total score was $0.795-0.905$, with a high correlation, indicating that the content measured by each dimension was basically consistent with that measured by the total questionnaire. Therefore, from this index, the structure of the questionnaire is acceptable.

Through the confirmatory factor analysis of the formal questionnaire data, the fitting degree of the constructed model and the actual data is tested as an index to test the correctness of the theoretical model. After conducting confirmatory factor analysis on the second batch of data, 17 questions were deleted (see Figure 2) and 19 questions were retained. The following criteria were referred to in the confirmatory factor analysis:

The value of $\mathrm{cmin} / \mathrm{df}$ was between 1 - 3, which meant that the model was in good fit. There are two forms of model fitting degree. CFI, TLI and GFI are used to describe the similarity degree of the model. Generally, 0.90 is taken as the standard, the closer to 1, the better. RMSEA and SRMR indexes are used to describe the degree of difference in the model, generally taking 0.08 as the standard, and the closer to 0 , the better. PNFI and PCFI are the indexes of reduced fitting degree, which are generally required to be greater than 0.50 .

In this study, $\mathrm{cmin} / \mathrm{df}=2.166, \mathrm{GFI}=0.884, \mathrm{AGFI}=0.845, \mathrm{CFI}=0.933, \mathrm{TLI}=$ 0.919, RMSEA $=0.070$, SRMR $=0.047$, and all the above indicators were within the standard, indicating that the model constructed in this study had a good fit. PCFI $=0.775$ and PNFI $=0.734$ both meet the standard, which means that the model has an acceptable degree of simplification. 


\subsection{Results Study 4}

\subsubsection{The Current Situation of Preschool Teachers' Caring Behavior}

Demographic characteristics of preschool teachers' caring behavior.

The self-compiled Questionnaire on Kindergarten Teachers' Caring Behaviors was used to test sample 4, and the results are shown in Table 5. Descriptive statistics and independent sample $\mathrm{T}$ test were used to analyze the collected effective data. The results showed that there was no significant difference in the caring behaviors of preschool teachers in terms of education background, but significant difference in the caring behaviors of preschool teachers in terms of teaching age, marital status, school location and school nature. Teaching experience more than 5 years of preschool teachers care line is significantly more than 5 years of preschool teachers, preschool teachers care behavior of married significantly more than the unmarried young teachers, and urban preschool teachers' caring behavior was significantly higher than that of the rural preschool teachers, preschool teachers care behavior of public schools is significantly higher than private kindergarten teachers.

\subsubsection{Analysis of Various Dimensions of Preschool Teachers' Caring behavior}

The mean and standard deviation of the five dimensions and the total table, as well as the mean and standard deviation of each item, were discussed by descriptive statistics method. The average score for each dimension is more than 3 points, from highest to lowest: understanding and support, respect and trust, class management, reflection and promotion, communication. The average value of the total scale exceeds 3 points, indicating that the caring behavior of preschool teachers as a whole reaches the level of above medium level (See Table 5).

Table 5. Differences of preschool teachers' caring behaviors in educational background, teaching age, marital status, school location and school nature.

\begin{tabular}{|c|c|c|c|c|}
\hline & & $(M \pm S D)$ & $p$ & $t$ \\
\hline \multirow{2}{*}{$\begin{array}{l}\text { Record of formal } \\
\text { schooling }\end{array}$} & Junior College and below (154) & $4.232 \pm 0.623$ & & \\
\hline & Bachelor and above (330) & $4.105 \pm 0.590$ & 0.495 & 2.162 \\
\hline \multirow{2}{*}{$\begin{array}{l}\text { Practical Year of } \\
\text { teaching experience }\end{array}$} & Less than 5 years $(310)$ & $4.086 \pm 0.568$ & & \\
\hline & More than 5 years (174) & $4.251 \pm 0.650$ & 0.046 & $-2.913^{*}$ \\
\hline \multirow{3}{*}{ Marital status } & Unmarried (283) & $4.045 \pm 0.650$ & & \\
\hline & & & & \\
\hline & Married (201) & $4.286 \pm 0.498$ & 0.008 & $-4.414^{* *}$ \\
\hline \multirow{2}{*}{$\begin{array}{l}\text { Location of } \\
\text { kindergarten }\end{array}$} & City (281 & $4.159 \pm 0.500$ & & \\
\hline & Rural areas (203) & $4.126 \pm 0.723$ & 0.000 & 0.589 \\
\hline
\end{tabular}




\subsection{Results Study 5}

\subsubsection{Measurement Process and Data Analysis}

Questionnaires were distributed through the network questionnaire star, SPSS24.0 was used for data input and analysis, and Amos24.0 was used for statistical analysis of structural equation model, including descriptive statistical difference test, variance analysis, Pearson correlation analysis and partial correlation. Due to the superior suitability of analyzing the complex relations among multiple latent variables simultaneously and controlling for measurement error, the method of structural equation modeling (SEM) using the Amos24.0 was employed to explore the relationships among the sets of constructs. For the SEM analyses, a number of indices were employed to indicate the robustness of fit. Specifically, besides the chi-square statistic, the fit indices used in the present study included the Root Mean Square Error of Approximation (RMSEA), the Non-Normed Fit Index (NNFI), the Comparative Fit Index (CFA) and the Goodness of Fit Index (GFI). In general, the criteria for an acceptable data fit include an RMSEA value below .08 and other fit index values above 0.90 .

\subsubsection{Results and Analysis}

\section{1) Descriptive statistics of each variable}

Table 6 summarizes the means, standard deviations, and the correlations among teachers' caring behavior, work performance, competence and occupational happiness. These four variables are significantly correlated.

2) The relationship between caring behavior and job performance. Chain mediating effect test

From the correlation analysis result, this research covers all variables were in significant positive correlation, to meet the intermediary effect test conditions in order to further clear the relationship between variables, using Amos 24.0 competency and professional well-being in the mediation role of preschool teachers care behavior and work performance testing, model fitting indicators are: chi square $/ \mathrm{df}=6.309, \mathrm{RMSEA}=0.105, \mathrm{SRMR}=0.033, \mathrm{CFI}=0.939, \mathrm{NNFI}=0.926$, visible data to the model fitting in the acceptable range (Wen, Hou, \& Herbert, 2004).

Table 6. Descriptive results and correlation of variables $(\mathrm{N}=484)$.

\begin{tabular}{|c|c|c|c|c|c|c|}
\hline & Mean & SD & Care Behavior & Competence & $\begin{array}{c}\text { Occupational } \\
\text { happiness }\end{array}$ & $\begin{array}{c}\text { Work } \\
\text { performance }\end{array}$ \\
\hline Care Behavior & 4.145 & 0.603 & 1.000 & & & \\
\hline Competence & 4.087 & 0.595 & $0.836^{* *}$ & 1.000 & & \\
\hline Occupational happiness & 4.002 & 0.686 & $0.735^{\star *}$ & $0.770^{\star *}$ & 1.000 & \\
\hline Work performance & 3.981 & 0.662 & $0.814^{* *}$ & $0.875^{\star *}$ & $0.786^{* *}$ & 1.000 \\
\hline
\end{tabular}

${ }^{*} p<0.05 ;{ }^{* *} p<0.01 ;{ }^{* * *} p<0.001$. 
According to the three steps of Baron and Kenny (Baron \& Kenny, 1986) to test the mediating effect, the path coefficient in Figure 3 was broken down and Bootstrap method (Preacher \& Hayes, 2008) was used to sample 1000 times to calculate the $95 \%$ confidence interval of the total direct effect and indirect effect of each path. The specific results are shown in Table 7.

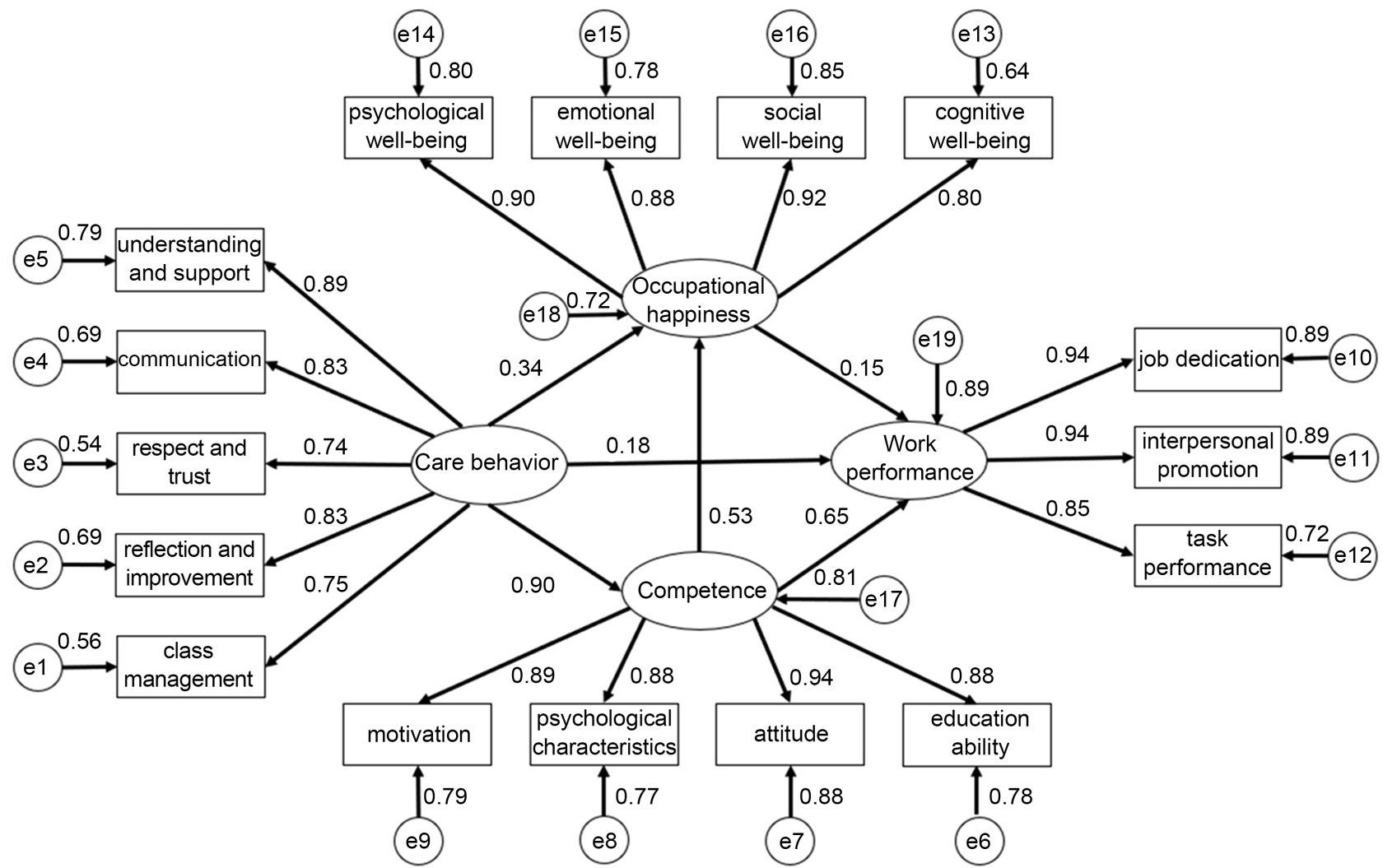

Figure 3. Diagram of the chained mediation model.

Table 7. Chain mediation between caring behavior and job performance.

\begin{tabular}{|c|c|c|c|c|c|c|c|c|c|}
\hline & \multirow{3}{*}{ Point Estimate } & \multirow{2}{*}{\multicolumn{2}{|c|}{ Product of coefficients }} & \multicolumn{6}{|c|}{ Boostrap 1000 time 95\% CI } \\
\hline & & & & \multicolumn{3}{|c|}{ Bias corrected } & \multicolumn{3}{|c|}{ Percentile } \\
\hline & & SE & $\mathrm{z}$ & Lower & Upper & $\mathrm{P}$ & Lower & Upper & $\mathrm{P}$ \\
\hline CBtoCTtoPHtoJP & 0.089 & 0.037 & 2.405 & 0.018 & 0.166 & 0.018 & 0.018 & 0.165 & 0.019 \\
\hline CBtoCTtoJP & 0.755 & 0.124 & 6.089 & 0.537 & 1.039 & 0.002 & 0.524 & 1.025 & 0.002 \\
\hline CBtoPHtoJP & 0.063 & 0.036 & 1.750 & 0.010 & 0.158 & 0.013 & 0.006 & 0.147 & 0.021 \\
\hline Total IE & 0.907 & 0.128 & 7.086 & 0.702 & 1.216 & 0.001 & 0.686 & 1.186 & 0.002 \\
\hline $\mathrm{DE}$ & 0.231 & 0.110 & 2.100 & 0.010 & 0.428 & 0.032 & 0.010 & 0.428 & 0.032 \\
\hline $\mathrm{TE}$ & 1.137 & 0.079 & 14.392 & 0.992 & 1.323 & 0.002 & 0.988 & 1.312 & 0.002 \\
\hline SIE diff & -0.692 & 0.133 & -5.203 & -1.010 & -0.457 & 0.001 & -0.975 & -0.438 & 0.002 \\
\hline
\end{tabular}

Note: CB is caring behavior, CT is competency, PH is occupational happiness, JP is job performance, Total IE is Total indirect effect, DE is direct effect, TE is Total effect, SIE Diff is whether there is significant difference in specific indirect effect between competency and occupational happiness. 
As shown in the figure, caring behavior can not only directly affect job performance, but also affect job performance through the intermediary chain between competence and occupational happiness. The model has a good fitting degree. Among them, caring behavior had a direct and significant predictive effect on job performance. Boostrap was used to test the mediating effect of competency and occupational happiness between caring behavior and job performance, and the mediating effect of competency was 0.755, (Boostrap 95\% CI $[0.537,1.039])$, the mediating effect of occupational happiness was 0.063 . (Boostrap 95\% CI $[0.010,0.158])$, the mediating effect of chain mediating competency on occupational happiness is 0.089 (Boostrap 95\% CI [0.018, 0.166]), and the three ranges do not include 0 , indicating that the total indirect effect of three significant mediating effects on job performance is 0.907 (Boostrap 95\% CI $[0.702,1.216])$, and the effect is significant without 0 , namely the variation of $90.7 \%$ of job performance can be explained by caring behavior. There are significant differences between the specific indirect effects of competency and occupational happiness, and the mediating effect of competency is greater than that of occupational happiness.

\section{Discussion}

\subsection{Structural analysis of Kindergarten Teachers' Caring Behavior}

This study found that the structure of preschool teachers' caring behavior includes five dimensions: understanding and support, communication, respect and trust, reflection and promotion, and class management. This is consistent with the findings of existing studies that positive teacher care is reflected in that preschool teachers should always pay attention to children, respect and understand them, communicate with them emotionally, affirm and encourage them (Chen, $\mathrm{Yu}, \&$ Xia, 2015). Teachers' cognition and understanding of students directly determine the way they interact with students, and teachers who lack correct cognition and understanding are likely to have behaviors against teachers' ethics (Wang, 2017). Therefore, understanding children is the premise for preschool teachers to implement caring behavior. Good communication and interaction are the key to high-quality early childhood education. Early childhood teachers should have the professional ability to listen, support and challenge children (McNaughton, Hamlin, McCarthy, Head-Reeves, \& Schreiner, 2008). The Professional Standards for Kindergarten Teachers (Trial Line) require teachers to be "good at listening, amiable and effective in communication with children". It can be seen that preschool teachers' caring behavior will run through the process of teacher-child communication. Respect for students is a basic manifestation of teacher care (Larson, 1999).

Teacher care is also reflected in contacting students, sharing personal experience with students, listening to students, communicating with students sincerely, and making physical contact with students in due time Such as pat on the 
back, hug, etc. (King \& Chan, 2011). This is consistent with the conclusion of this study that caring preschool teachers are able to respect and trust students, they are good at affirming students' contributions and encouraging students (Larson, 1999, King \& Chan, 2011) and can receive students in an open and sincere way (Hou, 2005).

\subsection{Analysis of the Current Situation of Kindergarten Teachers' Caring Behavior}

The results of this study show that the average total score of preschool teachers' caring behavior is 4.145 , which is 3 points higher than the theoretical average value, indicating that preschool teachers' caring behavior is above the medium level on the whole. The average score of each dimension from the highest to the lowest is understanding and support, respect and trust, class management, reflection and improvement, communication. Previous studies have found that preschool teachers with more than 5 years of teaching experience have more caring behaviors than teachers with less than 5 years of teaching experience, which is consistent with existing research results, but also inconsistent. Studies have found that the caring behavior of middle school teachers with a teaching experience of 5 - 25 years is significantly higher than that of teachers with a teaching experience of less than 5 years, and there is no significant difference in the level of caring behavior between teachers with a teaching experience of more than 25 years and those with a teaching experience of less than 5 years (Lei, 2014). The level of caring behavior of preschool teachers with $1-5$ years of teaching experience is significantly lower. From the perspective of occupational factors, teachers with 1 - 5 years of teaching experience have just started work, so there are certain deficiencies in professional ability and professional identity, and they have not found a sense of belonging. From the perspective of personal factors, teachers with 1 to 5 years of teaching experience are between 20 and 30 years old, and their personality development and maturity are not yet complete. They need others' care in themselves, so they are deficient in caring behavior. There are also studies that find that the teaching age is an important variable leading to the listening difference of kindergarten teachers. The preschool teachers who have just entered the service for $1-5$ years are significantly inferior to the preschool teachers with more than 5 years of teaching experience in actively listening to children. From the perspective of teachers' caring behavior, this study proves the objective existence that preschool teachers with $1-5$ years of teaching experience are relatively deficient in listening to children (Shi \& Chen, 2017). The caring behavior of married preschool teachers is higher than that of unmarried preschool teachers, because married preschool teachers have stronger family values than unmarried preschool teachers. Some of them are parents, and they are more likely to get along with children in the role of parents at work, so they give more care to children. The caring behavior of urban preschool teachers is higher than that of rural preschool teachers, which may be at- 
tributed to the tendency of national policies in the development of preschool education and the insufficient investment in rural preschool education, leading to a large gap between rural and urban preschool education on the whole $(\mathrm{Xu}$, 2015). City kindergarten than rural kindergarten at the same time, considering the factors such as economy and level of education in recruit teachers have more selective, the city of preschool teachers' qualities and moral character on the whole than rural children teach high, also pay more attention to preschool teachers' professional development level, studies have found that in the aspect of teachers' professional development level, kindergarten teachers in rural areas are the following questions: "is a new teacher, professional level is low; Second, lack of professional spirit, professional ability to be improved; Third, the faculty is not stable, the loss of personnel is more serious" (Cheng, 2013). From the perspective of teachers' caring behavior, this study proves the objective existence of "lack of professional spirit and need to improve professional competence" of rural preschool teachers.

Public care behavior of preschool teachers is higher than private preschool teachers, the possible reason is that the management of the public kindergarten is a private kindergarten sound, clear public kindergarten teachers' selection standard, strict, in-service preschool teachers' professional development level is high private kindergartens, so performance will be better in terms of child care. Therefore, attention should be paid to developing targeted training according to different types of teachers in the training of preschool teachers' caring ability in the future. Of course, the above results suggest that we should carry out training for unmarried teachers, rural teachers, private kindergarten teachers and teachers with 1 - 5 years of teaching experience when improving the level of preschool teachers' caring behavior. Kindergartens should strengthen teachers' learning and mastering of the theory of caring, and improve teachers' correct understanding of caring through practice activities such as caring experience exchange. By making use of educational practice activities, a variety of caring activities are designed and carried out consciously and purposefully, so as to improve teachers' caring ability step by step in the spiraling process of practical caring, reflective caring and improving caring (Chen et al., 2015).

\subsection{Teachers' Caring Behavior and Work Performance}

This study finds that there is a significant positive correlation between teachers' caring behavior and work performance, and teachers who give more caring behavior to students are more likely to achieve high performance, while teachers who give less caring behavior to students are more likely to achieve low performance. The conclusions of this study are consistent with the existing research on teacher-student relations (Dalton \& Watson, 1997; Kaur, Sambasivan, \& Kumar, 2013; Nowak-Fabrykowski, 2010; Perez, 2000; Song, 2006).

Nodding's ethics of care has been introduced into the field of education and has become a required topic for teachers in the United States (Rogers \& Webb, 
1991). In China, the Communist Party and the national government explicitly proposed "care for students" in the Code of Professional Ethics for Primary and Secondary Teachers (Ministry of Education, 2008).

\subsection{Competence, Occupational Happiness and Work Performance}

This study found a significant positive correlation between competence and work performance, and there was a significant positive correlation between occupational happiness and work performance of preschool teachers. The results of these studies are consistent with those of previous studies (Warr, 1959; Liu, 2016). According to the extended construction theory of positive emotions (Fredrickson, 2001), by happy, interest, proud, Thanksgiving elements such as positive emotions mainly has two core functions: one is the instantaneous expand functions such as expanding the scope of the attention, enhance cognitive flexibility, update and extend cognitive schemata is long-term construction function is based on the instantaneous expansion function, construct lasting cognitive social resources such as body, bring long-term benefits to individuals, such as improve the wisdom and creativity, increase mental flexibility, improve job performance, etc. (Garland et al., 2010; Chen \& Song, 2014).

Numerous existing research findings about middle school teachers, civil servants and enterprise employees, the stronger career happiness is, the higher job performance is. Career happiness is an important proximal factor affecting job performance. Career happiness of preschool teachers has a positive predictive effect on job performance (Wang, 2013).

\subsection{Mediating Role of Competence and Occupational Happiness in Teachers' Caring Behavior and Work Performance}

This study found that competence and occupational happiness play a partial mediating role between teachers' caring behavior and work performance in preschool teachers. This conclusion is consistent with the theoretical expectation that teachers' caring not only directly predicts preschool teachers' work performance but also influences the occurrence of work performance through the competence and occupational happiness of preschool teachers. These results are consistent with those of other studies (Nilsson, Ejlertsson, Andersson, \& Blomqvist, 2015; Wang, Su, Cui, \& Zhu, 2007). According to Porter \& Lawler (1968), Comprehensive Motivation Theory, individual abilities and traits (such as competency) will affect the impact of individuals on job satisfaction. The results of this study support the Comprehensive Motivation Theory that competency is the knowledge, skills and internal psychological structure of individuals (Delcourt, Gremler, van Riel, \& van Birgelen, 2016), the higher an individual's competence, the more competent he/she will be for his/her work, which will help teachers to experience a higher sense of happiness in their work, motivate them to be full of enthusiasm and vitality for their work, and thus achieve higher job performance. 


\section{Implications and Limitations}

The current study expands the understanding of the mechanisms underlying the effect of teachers' caring on work performance by supporting the role of competence and occupational happiness.

Furthermore, this study is the first to investigate competence and occupational happiness as mediation within the domain of teacher in a kindergarten setting. In clinical practice, the results of this study also provide teachers with inspiration.

First, preschool teachers should pay attention to the improvement of their own level of child care behavior, pay attention to the implementation of caring behavior in the communication with children at ordinary times, and internalize the concept of care into the internal requirements of their own professional quality improvement. In addition, the competence level of preschool teachers, as one of the important factors that influence teachers' professional happiness, is very important. Relevant education departments can carry out more training for preschool teachers, such as the national training plan for preschool teachers, which will help promote the competence of preschool teachers, reflect higher professional happiness, and then promote the development of preschool education.

\section{Conclusion}

This study expands the understanding of the mechanisms underlying the effect of teachers' caring on work performance by the mediating roles of competence and occupational happiness, and its findings are novel and insightful, both theoretically and practically. This study not only clarifies that preschool teachers' caring behavior positively predicts work performance but also supports the roles of their competence and occupational happiness as mediators in this relationship. Furthermore, this study expanded the application of the relationship between teachers and students in preschool teachers. In short, these findings suggest that competence and occupational happiness underlie the effect of preschool teachers' caring behavior on work performance. To this end, the current study offers an important foundation for future work.

\section{Acknowledgements}

We thank all the preschool teachers who participated in our study. We thank all the principals for their help in data collection.

\section{Conflicts of Interest}

The authors declare no conflicts of interest regarding the publication of this paper.

\section{References}

Baron, R. M., \& Kenny, D. A. (1986). The Moderator-Mediator Variable Distinction in Social Psychological Research: Conceptual, Strategic, and Statistical Considerations. 
Journal of Personality and Social Psychology, 51, 1173-1182. https://doi.org/10.1037/0022-3514.51.6.1173

Bloom, M., \& Noddings, N. (1996). The Challenge to Care in Schools: An Alternative Approach to Education. Communication Education, 45, 268-269.

Chen, C. H., \& Song, Y. X. (2014). The Impact Mechanism of Organizational Support Resources on Employee Happiness: A Two-Case Comparative Study. Journal of Management, No. 11, 1639-1645.

Chen, R. H., Yu, X. Q., \& Xia, J. Y. (2015). The Realistic Form and Development Strategy of Kindergarten Teacher Care. Research in Early Childhood Education, No. 4, 52-57.

Cheng, K. (2013). Research on Problems and Countermeasures of Professional Development of Rural Preschool Teachers. Academic Journal of Education, No. 8, 86-90.

Dalton, J., \& Watson, M. (1997). Among Friends: Classrooms Where Caring and Learning Prevail. Alameda, CA: Developmental Studies Center.

Delcourt, C., Gremler, D. D., van Riel, A. C. R., \& van Birgelen, M. J. H. (2016). Employee Emotional Competence: Construct Conceptualization and Validation of a Customer-Based Measure. Journal of Service Research, 19, 72-87. https://doi.org/10.1177/1094670515590776

Fornell, C. L. D. F. (1981). Evaluating Structural Equation Models with Unobservable Variables and Measurement Error. Journal of Marketing Research, 18, 39-50.

https://doi.org/10.1177/002224378101800104

Fredrickson, B. L. (2001). The Role of Positive Emotions in Positive Psychology: The Broaden-and-Build Theory of Positive Emotions. American Psychologist, 56, 218-226. https://doi.org/10.1037/0003-066X.56.3.218

Freeman, N., Swick, K., \& Brown, M. (1999). A Caring Curriculum Within an Early Childhood Teacher Education Program. Education, 120, 161.

Garland, E. L., Fredrickson, B., Kring, A. M., Johnson, D. P., Meyer, P. S., \& Penn, D. L. (2010). Upward Spirals of Positive Emotions Counter Downward Spirals of Negativity: Insights from the Broaden-and-Build Theory and Affective Neuroscience on the Treatment of Emotion Dysfunctions and Deficits in Psychopathology. Clinical Psychology Review, 30, 849-864. https://doi.org/10.1016/j.cpr.2010.03.002

Hair, J. F. et al. (2009). Multivariate Data Analysis: A Global Perspective (7th ed.). Upper Saddle River, NJ: Prentice Hall.

Hou, J. J. (2005). Caring Moral Education. Beijing: People's Education Press.

Kaiser, H. F., \& Rice, J. (1974). Little Jiffy, Mark IV. Educational and Psychological Measurement, 34, 111-117. https://doi.org/10.1177/001316447403400115

Kaur, D., Sambasivan, M., \& Kumar, N. (2013). Effect of Spiritual Intelligence, Emotional Intelligence, Psychological Ownership and Burnout on Caring Behaviour of Nurses: A Cross-Sectional Study. Journal of Clinical Nursing, 22, 3192-3202. https://doi.org/10.1111/jocn.12386

Ke, Z., \& Cui, Y. R. (2013). Profession Development of School-Based Teachers. Shanghai: East China Normal University Press.

King, P. C., \& Chan, T. C. (2011). Teachers' and Students' Perceptions on Teachers' Caring Behaviors. GERA-36th Annual Meeting, Savannah, Georgia, 21-22 October 2011.

Larson, A. (1999). A Descriptive Study of the Caring Behaviors of Physical Education Teachers. New York, NY: Teachers College, Columbia University.

Lei, H. (2014). CSI: A Framework for Analyzing Teachers' Caring Behavior. Shanghai Education and Research, No. 4, 64-67. 
Lei, H. (2015). Research on the Development Path of Middle School Teachers' Caring Behavior. Teacher Education Research, No. 2, 54-59.

Liu, X. J. (2016). Research on the Relationship between the Linkage of Competency Factors and Job Performance of R\&D Project Group Personnel. Master's Thesis, Harbin: Harbin Institute of Technology.

McNaughton, D., Hamlin, D., McCarthy, J., Head-Reeves, D., \& Schreiner, M. (2008). Learning to Listen: Teaching an Active Listening Strategy to Preservice Education Professionals. Topics in Early Childhood Special Education, 27, 223-231. https://doi.org/10.1177/0271121407311241

Ministry of Education (2008). Attachment: Professional Ethics of Primary and Secondary School Teachers (revised in 2008). Notice on Revising and Issuing the Code of Ethics for Primary and Secondary School Teachers (p. 1).

Mokkink, L. B., Terwee, C. B., Patrick, D. L., Alonso, J., Stratford, P. W., Knol, D. L. et al. (2010). The COSMIN Checklist for Assessing the Methodological Quality of Studies on Measurement Properties of Health Status Measurement Instruments: An International Delphi Study. Quality of Life Research, 19, 539-549.

https://doi.org/10.1007/s11136-010-9606-8

Nilsson, M., Ejlertsson, G. R., Andersson, I., \& Blomqvist, K. (2015). Caring as a Salutogenic Aspect in Teachers' Lives. Teaching \& Teacher Education, 46, 51-61. https://doi.org/10.1016/j.tate.2014.10.009

Nowak-Fabrykowski, K. (2010). Moving from Ethical Awareness to Deeper Understanding and Practice: Kindergarten Teachers' Experience with Developing Caring Dispositions in Children. Early Child Development \& Care, 180, 441-452. https://doi.org/10.1080/03004430802040922

Perez, S. A. (2000). An Ethic of Caring in Teaching Culturally Diverse Students. Education, 121, 102.

Porter, L. W., \& Lawler, E. E. (1968). What Job Attitudes Tell about Motivation. Harvard Business Review, 46, 118-126.

Preacher, K. J., \& Hayes, A. F. (2008). Asymptotic and Resampling Strategies for Assessing and Comparing Indirect Effects in Multiple Mediator Models. Behavior Research Methods, 40, 879-891. https://doi.org/10.3758/BRM.40.3.879

Rogers, D., \& Webb, J. (1991). The Ethic of Caring in Teacher Education. Journal of Teacher Education, 42, 173-181. https://doi.org/10.1177/002248719104200303

Shi, S., \& Chen, H. B. (2017). Analysis of the Status Quo of Kindergarten Teachers' Listening to Children. Research in Preschool Education, No. 6, 52-60.

Song, Y. (2006). Rational Thinking on Teachers' Virtues. Moral Education in Primary and Secondary Schools, No. 5, 6.

Wang, D. F. (2017). Discussion on the Relationship between Preschool Teachers' Ethics and Teachers' Professionalism. Education Guide, No. 9, 63-65.

Wang, D. F., Su, Y. J., Cui, H., \& Zhu, L. L. (2007). The Structure of Job Performance and Its Relationship with Competency. Psychological Science (China), 30, 770-773.

Wang, G. (2013). Characteristics of Occupational Happiness of Preschool Teachers and Its Relationship with Occupational Commitment. Psychological Development and Education, No. 6, 616-624.

Warr, J. A. (1959). Friction and Partial Denture Retention. Journal of Dental Research, 38, 1066-1074. https://doi.org/10.1177/00220345590380060301

Wen, Z. L., Hou, J. T., \& Herbert, M. (2004). Structural Equation Model Testing: Fitting Exponent and Chi-Square Criterion. Acta Psychologica Sinica, No. 2, 186-194. 
Wu, M. L. (2010). Statistical Analysis of Questionnaire: SPSS Operation and Application. Chongqing: Chongqing University Press.

Wu, X. X. (2012). Compassion: The Art of Connecting Teachers' and Children's Spirits-Inspiration from Suhomlinski. Research on Early Childhood Education, No. 10, 40-45.

Xiao, L. J. (2012). Relationship between Emotional Labor, Emotional Intelligence and Job Performance of Preschool Teachers. Master's Thesis, Changsha: Hunan Normal University.

$\mathrm{Xu}, \mathrm{Q}$. (2015). Teacher Allocation: The Key Task of the Current Rural Preschool Education Development. Preschool Education Research, No. 6, 22-25.

Zhu, X. Y. (2007). Competency Questionnaire for Preschool Teachers and Its Preliminary Application. Master's Thesis, Nanchang: Jiangxi Normal University. 